\title{
Wakaf Pendidikan Tinggi Sebagai Sumber Penjanaan Dana Dalam Kerangka Ekonomi Islam Di Malaysia
}

\author{
Baterah Alias ${ }^{*}$, Muhammad Hamizan Ab Hamid ${ }^{2}$, Baharuddin \\ Sayin $^{3}$, Mohd Afandi Mat Rani ${ }^{4}$, Azri Bhari ${ }^{5}$ \\ ${ }^{12345}$ Akademi Pengajian Islam Kontemporari (ACIS) Universiti Teknologi \\ MARA, \\ 40450 Shah Alam, Malaysia \\ *Pengarang Penghubung \\ bbaterah@uitm.edu.my
}

\begin{abstract}
ABSTRAK
Wakaf pendidikan tinggi penting bagi membiayai pendidikan pelajar yang kurang mampu untuk meneruskan pengajian serta membiayai perbelanjaan pengurusan universiti. Pada masa kini, wakaf pendidikan tinggi menjadi topik utama Kementerian Pengajian Tinggi sebagai suatu mekanisme pembiayaan perbelanjaan mengurus universiti tanpa perlu bergantung sepenuhnya kepada pihak kerajaan. Objektif kajian ini ialah untuk menganalisis institusi pendidikan tinggi di Malaysia yang menggunakan wakaf sebagai salah satu mekanisme penjanaan aset untuk menjalankan operasinya dengan mengambil Universiti Islam Malaysia (UIM) sebagai model kajian. Kajian menggunakan metode kajian perpustakaan dan lapangan untuk mendapatkan data primer dan sekunder. Kajian lapangan menggunakan instrument temubual dengan responden yang terlibat secara langsung dengan pengurusan tertinggi Universiti Islam Malaysia (UIM). Dapatan kajian menunjukkan Universiti Islam Malaysia (UIM) berjaya menjadikan wakaf sebagai aset penjanaan pendapatan dalam operasinya bagi melestarikan pendidikan tinggi di Malaysia. UIM menguruskan dana wakaf melalui hasil sewaan, sumbangan daripada Majlis Agama Islam dan badan korporat. Justeru, pelaksanaan wakaf pendidikan tinggi yang dilaksanakan di Universiti Islam Malaysia (UIM) boleh dijadikan sebagai model kepada institusi pendidikan lain dalam usaha membangunkan harta wakaf serta menjana pendapatan demi kelestarian wakaf pendidikan di Malaysia.
\end{abstract}

Kata Kunci: kerangka ekonomi Islam, penjanaan dana, wakaf pendidikan tinggi

\section{ABSTRACT}

Higher education wakaf is important to finance students who are less fortunate apart from assisting the management of the university. At present, higher 
education wakaf is becoming a hot topic of discussion at the Ministry of Education as this would allow the university to less financially dependent to the government. The aim of this study is to analyse the use of wakaf by higher education institution in Malaysia to generate funds for the university and Universiti Islam Malaysia (UIM) is chosen as sample of study. This study adopts library research and field work to collect the primary and secondary data. Interviews were conducted with those who directly involve in the management of UIM. Findings of this study showed that UIM is successful in generating funds through wakaf in order to sustain its management expenses. UIM manages wakaf funds from rental payments, fundings by Majlis Agama Islam Negeri (MAIN) and other corporate bodies. Thus, the implementation of higher education wakaf at UIM may become a good model for other universities in Malaysia to replicate for a sustainable management of the universities.

Keywords: Islamic economic framework, income generation, higher education wakaf

\section{Pendahuluan}

Wakaf pendidikan tinggi berupaya menjadi sumber penjanaan dana dalam kerangka ekonomi Islam di Malaysia kerana wakaf merupakan aset yang penting dalam pembangunan masyarakat Islam. Wakaf pendidikan tinggi menyediakan peluang dan kemudahan kepada masyarakat untuk mendapatkan ilmu pengetahuan dan juga merupakan institusi yang menyediakan ruang untuk umat Islam melakukan amal kebajikan. Aspek kelestariannya memainkan peranan penting bagi mengekalkan pembangunan institusi pendidikan tinggi berkonsepkan wakaf dan berfungsi sebagaimana yang diharapkan. Usaha memperkasakan wakaf pendidikan tinggi seperti wakaf tunai dan saham wakaf perlu dipergiatkan sebagai anjakan paradigm sekaligus membangunkan taraf pendidikan masyarakat dan merancakkan lagi pembangunan ekonomi umat Islam secara keseluruhannya.

Objektif kajian ini ialah untuk menganalisis institusi pendidikan tinggi di Malaysia yang menggunakan wakaf sebagai salah satu mekanisme penjanaan dana untuk menjalankan operasinya dengan mengambil Universiti Islam Malaysia (UIM) sebagai model kajian. UIM merupakan sebuah institusi pendidikan pertama di Malaysia yang mendapat perkenan Majlis Raja-Raja Melayu dan memperoleh sumbangan dana wakaf daripada pelbagai pihak sama ada syarikat, pertubuhan mahupun individu bagi menjalankan operasinya. 
Wakaf Pendidikan Tinggi Sebagai Aset Penjanaan Dana

\section{Metode Kajian}

Kajian ini menggunakan metode kajian perpustakaan dan lapangan untuk mendapatkan data primer dan sekunder. Dokumen-dokumen berkaitan Kolej Islam Malaya (KIM) dan juga UIM diselidiki bagi memperoleh maklumat penting berkenaan sejarah sampel yang dikaji. Kajian lapangan juga diadakan dengan menggunakan metode temubual. Beberapa responden yang terlibat secara langsung dengan pengurusan tertinggi Universiti Islam Malaysia (UIM) telah ditemubual bagi memperoleh data terkini berkaitan pengurusan UIM.

\section{Analisis dan Perbincangan}

\subsection{Wakaf Sebagai Mekanisme Penjanaan Ekonomi Pendidikan Tinggi Di Malaysia}

Wakaf pendidikan tinggi merupakan suatu aset dalam kerangka ekonomi Islam bagi membiayai pendidikan pelajar yang kurang mampu untuk meneruskan pengajian serta membiayai perbelanjaan pengurusan universiti. Pada masa kini, wakaf pendidikan tinggi menjadi topik utama Kementerian Pengajian Tinggi sebagai suatu mekanisme pembiayaan perbelanjaan mengurus universiti tanpa perlu bergantung sepenuhnya kepada pihak kerajaan.

Sektor pendidikan tinggi merupakan elemen komponen pendidikan yang amat penting di dalam memacu pertumbuhan ekonomi sesebuah negara. Institusi pendidikan tinggi terutamanya Universiti Awam (UA) berperanan menghasilkan sumber manusia yang berpengetahuan dan berkemahiran tinggi menjadi peneraju kepada kemajuan ekonomi negara. Menyedari kepentingan melahirkan graduan berkopentensi, pihak kerajaan telah menyalurkan pelbagai bantuan terutamanya bantuan kewangan daripada dana awam bagi membiayai kos pembangunan dan operasi institusi tersebut (Asharaf Mohd Ramli et al., 2016).

Bajet 2016 telah memperuntukkan RM13.378 bilion untuk Kementerian Pendidikan Tinggi (KPT) berbanding RM15.785 bilion dalam Bajet 2015 (Kementerian Kewangan Malaysia, 2015). Jumlah keseluruhan menunjukkan pengurangan peruntukan kepada KPT sebanyak RM 2.4 bilion daripada tahun sebelumnya. Keadaan ini menyebabkan Institusi Pengajian Tinggi terpaksa menanggung perbelanjaan kos operasi yang agak tinggi berbanding sebelum ini (Ahmad Shaifful Anuar, 2015). 
Menurut Abdul Halim Sunny (2007:33) kos untuk membiayai pendidikan tinggi juga semakin mahal berikutan yuran pengajian semakin meningkat terutama bagi kursus-kursus kritikal dalam bidang sains dan teknologi seperti perubatan, sains kesihatan, farmasi, kejuruteraan, sains angkasa dan lain-lain. Tidak terkecuali juga bidang sastera dan agama yang merupakan bidang tradisi bagi majoriti pelajar Bumiputera Muslim. Oleh yang demikian, kaedah terbaik untuk mengatasi masalah ini adalah dengan meningkatkan kemampuan Universiti Awam (UA) untuk berdikari dari sudut ekonomi dan kewangan.

Bertepatan dengan hasrat mantan Menteri Pengajian Tinggi, Datuk Seri Idris Jusoh menyatakan bahawa langkah pengurangan bajet untuk Kementerian Pengajian Tinggi adalah selaras dengan Pelan Pembangunan Pendidikan Malaysia (Pendidikan Tinggi) atau PPPM (PT) 2015-2025 iaitu menekankan langkah memastikan kemapanan kewangan Universiti Awam (UA) dengan cara mengurangkan kebergantungan pada sumber kerajaan. Oleh itu, semua UA perlu mengurangkan kebergantungan terhadap pembiayaan kerajaan dan menggunakan kepakaran, aset serta konsultasi swasta bagi meningkatkan pendapatan dan membiayai kos universiti susulan pengurangan bajet kementerian (Utusan Online, 2015).

Antara mekanisme yang telah diambil oleh kerajaan untuk mengurangkan beban kewangan adalah melalui pelancaran Pelan Strategik Pendidikan Tinggi Negara 2020. Dalam pelan tersebut, universiti telah diberi kuasa autonomi untuk menjana pendapatan sendiri dengan mengurangkan perbelanjaan awam dalam pemberian subsidi kerajaan daripada $90 \%$ kepada $70 \%$ daripada jumlah perbelanjaan universiti awam menjelang tahun 2020 (MOHE, 2007). Justeru itu, salah satu instrumen untuk memastikan kemapanan kewangan Universiti Awam (UA) mengurangkan kebergantungan pada sumber kerajaan adalah dengan mengimplimentasikan pembiayaan pendidikan melalui kaedah wakaf.

Pembiayaan pendidikan melalui wakaf sebenarnya telah terbukti mendapat tempat di Malaysia dengan wujudnya universiti wakaf pertama di Malaysia iaitu Universiti Islam Malaysia (UIM) yang terletak di Cyberjaya. Penubuhan UIM sebagai satu legasi kesinambungan daripada Kolej Islam Malaya (KIM) telah berjaya diaktifkan semula setelah tamat operasinya pada tahun 1970. Penubuhan UIM dianggap sebagai pelopor wakaf pendidikan negara dan akan dijadikan panduan untuk penubuhan wakaf institusi pendidikan tinggi yang lain di masa akan datang. 
Wakaf Pendidikan Tinggi Sebagai Aset Penjanaan Dana

\subsection{UIM Sebagai Model Wakaf Pendidikan Tinggi}

Model wakaf pendidikan tinggi UIM merupakan yang pertama di Malaysia mendapat perkenan Majlis Raja-Raja Melayu dan memperoleh sumbangan dana wakaf daripada pelbagai pihak sama ada syarikat, pertubuhan dan individu. Penubuhan UIM bukanlah satu duplikasi kepada Universiti Islam Antarabangsa Malaysia (UIAM) dan Universiti Sains Islam Malaysia (USIM) kerana ia adalah pusat penyelidikan khusus bagi pengajian Sarjana dan $\mathrm{PhD}$ serta sebagai penyambungan kepada sebuah institusi pengajian yang telah pun tertubuh sebelum ini. UIM dahulunya merupakan Kolej Islam Malaya (KIM) yang ditubuhkan pada tahun 1955 dengan perkenan Raja-Raja Melayu ketika itu (Ruzy Adila Idris, 2013).

Wakaf pendidikan tinggi UIM hanya menjalankan aktiviti pembelajaran di peringkat pascasiswazah kerana penubuhan asal KIM dahulu merupakan sebuah institusi pendidikan tinggi bertaraf university. Pengiktirafan yang diberikan kepada kualiti akademik bagi program sijil atau diploma keluaran KIM adalah setaraf dengan ijazah pertama Universiti Al-Azhar, Mesir (Abd Talib Hamid \& Fidaus Ahmad Azzam, 2003).

Objektif penubuhan UIM adalah menyelaraskan hubungan dalam kalangan pelbagai etnik di Malaysia melalui ajaran Islam yang universal. Penubuhan ini bertepatan dengan tema yang dipegang oleh UIM iaitu kebijaksanaan global. Pencapaian kejayaan turut disokong dengan visi universiti dalam menggabungkan pengetahuan dan kebijaksanaan sebgai satu kesatuan untuk melairkan ilmuan dan pemikir yang berwawasan dan berimbang. Manakala misi yang direncanakan adalah berdasarkan penyediaan orientasi pendidikan, pengajaran dan pendidikan pascasiswazah yang berteraskan ilmu dan kebijaksanaan (Bulletin UIM, Mac 2014).

Hasil penubuhan UIM ini merupakan lambang solidariti dan kerjasama Majlis Raja-Raja Melayu di Malaysia. Pelan pendidikan di UIM menawarkan pelbagai bentuk inovasi bagi meneroka dimensi yang berkaitan dengan penyelidikan baharu daripada aspek pengajaran interaktif yang berorientasikan penyelidikan, latihan kemahiran, seminar dan pelbagai wacana intelek terutamanya dalam program Sarjana dan $\mathrm{PhD}$. Pendidikan secara holistik menjadi fokus utama UIM dalam memenuhi keperluan dan permintaan tokoh ilmuan Islam dengan secara komprehensif dan fleksibel (Bulletin UIM, Mac 2014). 


\subsection{Penjanaan Dana UIM}

Aspek pendanaan UIM merupakan satu perkara yang penting bagi melestarikan operasi perjalanan terutamanya melibatkan pembiayaan dalam tempoh yang panjang. Pendanaan UIM banyak dibantu oleh hasil perkembangan manfaat wakaf KIM yang telah berkembang selepas operasi KIM terhenti pada tahun 1970. Hasil daripada aset wakaf berupa tanah dan sewaan aset KIM tersebut masih berjalan sehingga sekarang. Pembangunan dan pembiayaan operasi KIM pada tahun 1955 sebahagian besarnya diperolehi daripada hasil wakaf dan derma orang perseorangan, negeri dan korporat (Abd Talib Hamid \& Fidaus Ahmad Azzam, 2003).

Perkembangan harta wakaf KIM telah memberikan peluang kepada Lembaga Penasihat Penyelaras Pelajaran dan Pendidikan Agama Islam (LEPAI) melalui mesyuarat majlis Kebangsaan Hal Ehwal Ugama Islam (MKI) bersetuju bagi mengaktifkan kembali KIM melalui penubuhan UIM. Kini penubuhan UIM telah mempunyai hasil yang mampu menampung kos perbelanjaan bagi sebuah universiti bertaraf swasta. Pendapatan Universiti Islam Malaysia (UIM) adalah seperti berikut:

Jadual 1: Pendapatan tetap UIM

\begin{tabular}{|l|l|c|}
\hline Bil & \multicolumn{1}{|c|}{ Perkara } & Jumlah (RM) \\
\hline 1. & $\begin{array}{l}\text { Pendapatan sewaan tanah wakaf di } \\
\text { Jalankampung Jawa, Klang }\end{array}$ & $\begin{array}{c}\text { RM 1,034,000.00 } \\
\text { setahun }\end{array}$ \\
\hline 2. & $\begin{array}{l}\text { Sebahagian daripada sewa tanah } \\
\text { wakaf di Petaling Jaya }\end{array}$ & RM 3,500,000.00 \\
\hline 3. & $\begin{array}{l}\text { Peruntukan Dana Geran Tahunan } \\
\text { kerajaan untuk membiayai } \\
\text { perbelanjaan UIM bagi tempoh } \\
\text { selama 5 tahun mulai 2014 hingga } \\
\text { 2018 }\end{array}$ & $\begin{array}{l}\text { RM 30 juta } \\
\text { setahun }\end{array}$ \\
\hline 4. & $\begin{array}{l}\text { Sumbangan tetap daripada Majlis } \\
\text { Agama Islam Pulau Pinang sebanyak }\end{array}$ & $\begin{array}{c}\text { RM 100,000.00 } \\
\text { setahun }\end{array}$ \\
\hline
\end{tabular}

Sumber: Minit mesyuarat MKI kali ke-58, 13 Februari 2015

Jadual 2: Anggaran pendapatan tidak tetap UIM 2013/2014

\begin{tabular}{|l|l|l|}
\hline Bil & Perkara & Jumlah (RM) \\
\hline 1. & 30 ekar tanah dan bangunan-bangunan di & RM 84,000,000.00 \\
\hline
\end{tabular}




\begin{tabular}{|l|l|l|}
\hline & $\begin{array}{l}\text { jalan Universiti yang disewa atas kadar } \\
\text { minimum oleh Universiti Islam } \\
\text { Antarabangsa (UIAM) }\end{array}$ & setahun \\
\hline 2. & $\begin{array}{l}\text { Rumah-rumah di Jalan Cawan, Petaling } \\
\text { Jaya }\end{array}$ & $\begin{array}{l}\text { RM 432,800.00 } \\
\text { setahun }\end{array}$ \\
\hline 3. & $\begin{array}{l}\text { Rumah banglo di Jalan Gasing, Petaling } \\
\text { Jaya }\end{array}$ & $\begin{array}{l}\text { RM159,950.00 } \\
\text { setahun }\end{array}$ \\
\hline
\end{tabular}

(Sumber: Temubual Ketua Pegawai Eksekutif Dana UIM, 15 Disember 2015)

Jadual 3: Aset tetap yang dimiliki oleh Lembaga Amanah Kolej Islam Malaya (LAKIM) bagi pihak Universiti Islam Malaysia (UIM)

\begin{tabular}{|c|l|c|}
\hline $\begin{array}{c}\text { Bi } \\
\mathbf{l}\end{array}$ & \multicolumn{1}{|c|}{ Perkara } & Jumlah (RM) \\
\hline 1. & Tunggakan hasil sewa tanah wakaf & RM 7,000,000.00 \\
\hline 2. & Sumbangan LAKIM & RM 3,500,000.00 \\
\hline 3. & $\begin{array}{l}\text { Sumbangan Majlis Agama Islam Negeri- } \\
\text { Negeri }\end{array}$ & RM 9,000,000.00 \\
\hline 4. & Sumbangan daripada Syarikat GLC & RM 2,000,000.00 \\
\hline 5. & Sumbangan daripada Luar Negara & RM 5,000,000.00 \\
\hline 6. & Yuran pengajian & RM 2,550,000.00 \\
\hline
\end{tabular}

(Sumber: Temubual Dr. Siti Normala Sheikh Obid, 10 September 2015)

Universiti Islam Malaysia (UIM) telah dizahirkan dengan perkenan Majlis Raja-Raja Melayu dan telah menerima dana wakaf berjumlah RM5.18 juta daripada tujuh pihak yang terdiri daripada syarikat, pertubuhan dan individu. Wakaf tersebut telah disampaikan Duli Yang Maha Mulia Sultan Selangor dalam satu majlis yang diadakan di Istana Kayangan Shah Alam.

Jadual 4: Penyumbang Wakaf UIM

\begin{tabular}{|c|l|c|}
\hline $\begin{array}{c}\text { Bi } \\
\mathbf{1}\end{array}$ & \multicolumn{1}{|c|}{ Nama } & Jumlah (RM) \\
\hline 1. & Permodalan Nasional Bhd & RM 5 juta \\
\hline 2. & Shahpadu Corp Sdn Bhd & RM 100,000.00 \\
\hline
\end{tabular}




\begin{tabular}{|c|l|c|}
\hline 3. & $\begin{array}{l}\text { Datuk Dr Harun Din mewakili } \\
\text { bekas pelajar Kolej Islam Malaya } \\
\text { (KIM) }\end{array}$ & RM 30,675.00 \\
\hline 4. & $\begin{array}{l}\text { Waris dan warga KIM Petaling } \\
\text { Jaya }\end{array}$ & RM 17,000.00 \\
\hline 5. & $\begin{array}{l}\text { Alumni Kolej Islam (ALKIS) - } \\
\text { diwakili Datuk Sallehuddin Ishak }\end{array}$ & RM 11,000.00 \\
\hline 6. & $\begin{array}{l}\text { Persatuan Bekas Pelajar KIM dan } \\
\text { bekas ketua pelajar Kolej islam } \\
\text { Klang tahun 1975 - diwakili Puzi } \\
\text { Dahman }\end{array}$ & RM 10,000.00 \\
\hline
\end{tabular}

(Sumber: Sinar Harian 7 September 2012).

\subsection{Kelestarian Wakaf Pendidikan Tinggi UIM}

Sumbangan berbentuk wakaf telah dilaksanakan sejak penubuhan Kolej Islam Malaya (KIM) pada tahun 1955 dan merupakan pusat pendidikan tinggi berasaskan wakaf di negara ini. Almarhum Sultan Sir Hisamuddin Alam Shah, Sultan Selangor ketika itu telah mewakafkan Istana Jamaah di Kampung Jawa Kelang yang dijadikan kampus pertama Kolej Islam Malaya (KIM). Penubuhan KIM telah dirasmikan oleh baginda pada 8 April 1955 yang dihadiri oleh Raja-Raja Melayu dan wakil baginda (Abd Manaf Hj Ahmad, 2012).

Kini KIM telah diaktifkan sebagai Universiti Islam Malaysia (UIM) yang dipersetujui dan direstui dalam Persidangan Majlis Raja-Raja Melayu kali ke-222 pada 12 Oktober 2010. Sumbangan wakaf kepada KIM/UIM telah disumbangkan oleh pihak Istana, kerajaan dalam dan luar Negara, Majlis Agama Islam Negeri-Negeri, badan korporat, syarikat dan individu. Kelangsungan Pendidikan Islam melalui KIM/UIM bersumberkan oleh sumbangan daripada pelbagai pihak dari dahulu sehinggalah sekarang.

Bagi memastikan amanah berbentuk wakaf diteruskan oleh UIM, keperluan sumbangan pelbagai pihak daripada badan korporat dan orang perseorangan diperlukan bagi melaksanakan pendidikan Islam secara konsisten. Dana juga diperlukan bagi membiayai kajian dan penyelidikan yang amat kurang ditumpukan oleh negara Islam. Data menunjukkan, kajian yang dilaksanakan oleh negara Islam hanya merangkumi $0.5 \%$ daripada keseluruhan kajian dan penyelidikan yang dibuat diseluruh dunia (Mohd Zul Fadlain, 2015). 
Kekurangan umat Islam dalam penyelidikan telah mendorong UIM menjadi sebuah institusi yang mempelopori kaedah penyelidikan semasa. Di samping UIM berperanan sebagai hub-penyelidikan, ia juga menjadikan wakaf berperanan dalam pelaksanaan pendidikan Islam. UIM memperolehi pelbagai sumber menerusi wakaf dan salah satu manfaat sumbangan wakaf tersebut dilaburkan dalam dana pelaburan yang patuh syariah dengan mendapatkan kelulusan oleh panel jawatankuasa syarie UIM. Manakala dividen dan keuntungan hasil pelaburan ini akan digunakan bagi tujuan 20 peratus untuk kos operasi, 50 peratus untuk kos penyelidikan dan 15 peratus untuk tujuan pelaburan akademik dan projek khas (Mohd Zul Fadlain, 2015).

Dana wakaf ini juga akan digunakan untuk membeli aset kekal sama ada bangunan atau harta tanah. Hasil pelaburan dan keuntungan akan dimanfaatkan sepenuhnya melalui penyediaan fasiliti dan prasarana bagi aktiviti keilmuan merangkumi program pengajaran dan pembelajaran, penyelidikan dan inovasi sert khidmat komuniti yang menjadi aktiviti teras universiti. Antara projek dan aktiviti tersebut termasuklah bantuan kewangan untuk pembelajaran kepada pelajar, bantuan kewangan untuk kursus-kursus dan aktiviti pembangunan pelajar, prasarana dan bantuan untuk penyelidikan, pembiayaan bagi pembangunan projek khas seperti pembinaan dewan kuliah, perolehan aset, kenderaan, prasarana dan peralatan bagi pengajaran, penyelidikan dan penerbitan serta perkhidmatan di fakulti dan kolej kediaman (Mohd Zul Fadlain, 2015).

Rajah 1: Penggunaan Pembiayaan Hasil Pelaburan Wakaf Pendidikan UIM

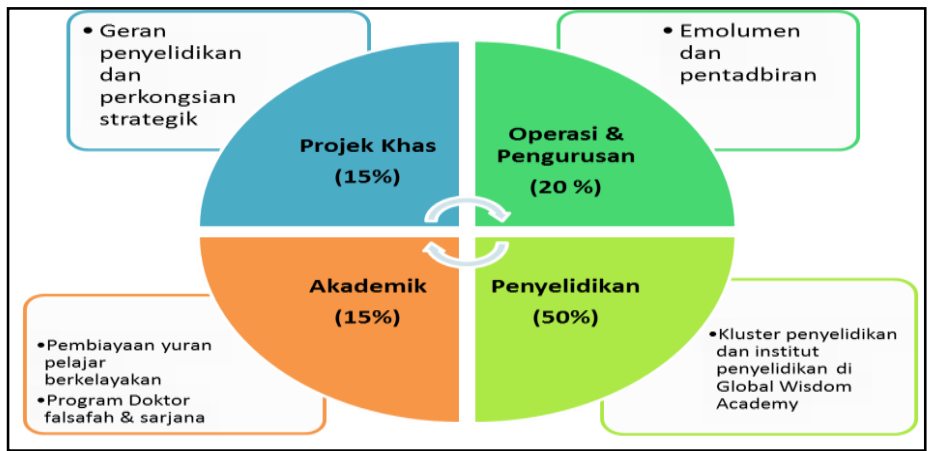

Sumber: Bulletin UIM Bil 5/2015 


\section{Kesimpulan}

Wakaf dalam bidang pendidikan adalah pelaburan untuk melahirkan modal insan yang berkualiti. Penubuhan UIM sebagai sebuah universiti berorientasikan wakaf di Malaysia diharapkan dapat memberi impak yang besar dalam agenda kemajuan terutamanya dalam institusi wakaf pendidikan. Sejarah dan kecemerlangan universiti yang dilaksanakan oleh negara lain sudah pun membuah hasil dengan kemunculan perkembangan pusat pengajian ulung menerusi Universti Oxford, Universiti Al-Azhar, Universiti Cardova di Andalus dan sebagainya. Universiti ini terus maju dengan hasil dan sumbangan daripada institusi wakaf. Penubuhan Universiti Al-Azhar merupakan contoh pendidikan yang berjaya membangun dan berkembang melalui harta wakaf. Pembiayaan Universiti Al-Azhar yang dibina sejak 1000 tahun dahulu telah memberikan yuran pengajian yang minima kepada pelajar Islam di seluruh dunia.

Di Malaysia, UIM perlu memainkan peranan utama dalam mempromosikan kepentingan wakaf dan menggalakkan lebih ramai umat Islam untuk berwakaf. di samping turut menyumbang kepada perkembangan bidang pendidikan dan penyelidikan. Oleh itu, UIM seharusnya merancang strategi yang lebih komprehensif bagi membangunkan institusi wakaf pendidikan tinggi setaraf dengan institusi pendidikan yang tenama di dunia. Potensi ini bukan sahaja memperkenalkan UIM di serata dunia malah memberikan implikasi yang besar terhadap pendidikan di negara ini sebagai sebuah hub pendidikan serantau.

\section{Penghargaan}

Sekalung penghargaan dan jutaan terima kasih ditujukan kepada Kementerian Pengajian Tinggi Malaysia (KPT) yang telah memberikan peluang kepada penyelidik menjalankan penyelidikan geran wakaf (LRGS14-002-0003).

\section{Rujukan}

Abd Manaf Hj Ahmad (2012). Mengapa Perlunya Universiti Islam Malaysia. Selangor: Matang Sdn Bhd.

Asharaf Mohd Ramli \& Mustafa Omar Mohamed (2016), "Cabaran Pembiayaan Sektor Pengajian Tinggi Awam Di Malaysia: Potensi Instrumen Wakaf Tunai", dalam Mohd Solahuddin 
Shahruddin, Sinergisme Wakaf Pendidikan Tinggi Di Malaysia, Shah Alam: Institut Kajian Zakat Dan Wakaf.

Ahmad Shaifful Anuar Ahmad Shukor (2015), Potensi Wakaf Pendidikan Tinggi di Malaysia, Kuala Lumpur: Dewan Bahasa dan Pustaka.

Abdul Halim Sunny (2007). Dana Wakf Untuk Pendidikan: Satu Tinjauan Awal. Jurnal Pengurusan JAWHAR. Vol.1 No.2, h. 3344

Abd Talib Hamid \& Fidaus Ahmad Azzam (2003). Kolej Islam Malaya : Sejarah dan Perkembangan, Cet.1. Selangor : Kolej Islam Sultan Alam Shah, Kelang.

Bulletin UIM Mac 2014

Bulletin UIM Bil 5/2015

Bulletin UIM Bil 6/2015

Cenderamata Ulang Tahun Ke-20 Kolej Islam Malaya, (1955-1975).

Hasyeilla Abd Mutalib et.al., (2014). "Universiti Islam Malaysia: Transformasi Pembangunan Institut Wakaf Pendidikan", Jurnal Pengurusan JWZH, Vol.8, No.2.

Laman Web Universiti Islam Malaysia Dilayari pada 3 Januari 2015 daripada http://yauim.uim.edu.my/

Minit Mesyuarat Majlis Kebangsaan Bagi Hal Ehwal Ugama Islam Malaysia Kali Ke-56, 16 Januari 2014

Minit mesyuarat MKI kali ke-58, 13 Februari 2015.

Mohd Syakir Mohd Taib et.al., (2014). “ Universiti Islam Malaysia (UIM) Wakaf Pendidikan Tinggi Pertama Di Malaysia" dalam Wan Kamal Mujani, Pelestarian Institusi Wakaf : Memperkasakan Pendidikan Tinggi Negara. Bangi : Fakulti Pengajian Islam UKM, h. 369-378

Mohd Turmadzi Madun ( 5 Januari 2016). UIM tubuh kelas kerabat diraja, Kosmo Online. Dilayari daripada 18 Disember 2015 daripada laman sesawang http://www.kosmo.com.my/kosmo/content.asp?y=2015\&dt=0703 \&pub

Ram Al Jaffri Saad (10/03/2014), Menanti Wujudnya Universiti Wakaf Pertama di Malaysia, Utusan Online. Dilayari pada 23 Februari 2015 daripada laman sesawang http://www.utusan.com.my/utusan/Rencana/20140101/re_07/Me nanti-wujudnya-universiti-wakaf-pertama-di-Malaysia

Ruzy Adila Idris (20 Januari 2013). MPN mahu Universiti Islam Malaysia diwujud segera, Sinar Harian. Dilayari pada 13 Ogos 2015 daripada laman sesawang 
http://www.sinarharian.com.my/nasional/mpn-mahu-universitiislam-malaysia-diwujud-segera.

Sinar Harian Online. Dilayari pada 17 Disember 2015. daripada http://www.sinarharian.com.my/nasional/universiti-islammalaysia-terima-dana-wakaf-rm5-18-juta-1.82722

Sinar Harian Online. Dilayari pada 21 Disember 2015 daripada http://www.sinarharian.com.my/nasional/universiti-islammalaysia-terima-dana-wakaf-rm5-18-juta-1.82722

Surat Permohonan Melantik Universiti Islam Malaysia Sebagai Wakil Naziran bagi Harta Wakaf Kolej Islam Malaya (KIM) \& Wakaf UIM, 15 Mei 2014.

Utusan Melayu, 20 September 1946, h.12.

\section{Statut}

Enakmen Wakaf Selangor 2015, Enakmen No. 15 Tahun 2015.

Enakmen Pentadbiran Agama Islam Negeri Selangor 2003, Enakmen No. 1 Tahun 2003.

\section{Temubual}

Encik Mohd Zul Fadlain Bin Abdullah, Ketua Pegawai Eksekutif Dana UIM pada 15 Disember 2015 jam 3.00 petang di Perpustakaan Utama UIM.

Dr. Siti Normala Sheikh Obid, Setiausaha Lembaga Amanah Kolej Islam Malaya (LAKIM) pada 10 September 2015 jam 10.00 pagi di pejabat rasmi LAKIM.

\section{Website}

Website UIM : http://www.uim.edu.my/v2/index.php/about-uim/uim-atglance/history-of-uim. 22 September 2016 Website MOHE:

https://engine.um.edu.my/docs/librariesprovider17/forms-and-circularsaccreditation guidelines/pelanstrategikpengajiantinggi2020.pdf?sfvrsn=2. 12 September 2016 